\title{
Development of a non-linear process control test bench and empirical investigation of control performance
}

\author{
Harshit Bhadauriya*, Harsh Kapadia, J B Patel and Alpesh Patel \\ Instrumentation \& Control Engineering, Institute of Technology, Nirma University, Ahmedabad, India
}

\section{(C2016 ACCENTS}

\begin{abstract}
Non-linear systems have been challenging for control engineers since a long time. In this paper a laboratory test bench is presented which can demonstrate a non-linear process. A conical tank is used to depict non-linearity for this study. A conical tank shows non-linearity in its model due to its variation in area with respect to its height. As the level of fluid inside the conical tank varies, time constant and gain of the process will also vary. In this study investigations are performed to check the control performance of the non-linear process at different operating points. LabVIEW is used as computational tool to implement control strategies. In future a low cost embedded system using an Advanced RISC Machine (ARM) based controller will be developed in such a manner that it will perform the computational task and LabVIEW will only be used as a tool to monitor the operation inside the conical tank in real time. The paper includes mathematical modelling, system integration, implementation, results and future scope.
\end{abstract}

\section{Keywords}

Non-linear process, Conical tank, ARM based controller, Mathematical modelling.

\section{Introduction}

Non-linear processes are very frequently found in various chemical plants. They remain a challenge for control engineers due their functionality and behaviour. Linear systems are much easier to control due their predictable parameters. But dynamics of a non-linear system are dependent upon many other factors affecting the process that keeps changing during the course of the whole process. So a control strategy is required that can continuously monitor the change in the parameters of the system and takes actions [1]. During the process of finding a strategy to control a non-linear system, a particular mechanism is required in order to keep the output of the non-linear process within a specific range. The objective of this paper is to check the limitations of the control strategies applicable to a linear system when they are applied to non-linear systems. Here a conical tank is used in order to have a non-linear behaviour in the test bench as area of the tank keeps getting varied with respect to its height. LabVIEW is used in order to implement the PID controller and an ARM based controller that is connected to the LabVIEW is used to get the sensor's data from the process and to generate suitable PWM to run water pump according to the PID's output.

*Author for correspondence

170
Conical tanks are being used by industries now days due to their ability to discharge the material inside the tank completely by the influence of gravity itself. No residue remains inside the tank and no motorised pumps are required to remove the slurry or whatever material remains at the bottom of a regular cylindrical tank. Due to this utility of conical tanks, they are being popular in cement industries, waste water treatment plants and many more.

During the literature survey it is found that most of the researchers have assumed different parameters for the conical tank and have derived their results in simulation environments [2]. Hardware setups and implementation of control strategies on a conical tank has not been done by many. Aim of this paper would be to prove that the control strategies like PID that are very successful in controlling a linear process are not efficient solutions for the control of non-linear processes. In future it would be aimed to implement a strategy to control the level inside the conical tank using a low cost embedded system on a proper hardware.

\section{Mathematical modelling}

In order to determine a system which can be studied and understood in a proper way it is required to have a mathematical model of that system [3]. Figure 1 [2] shows the functional diagram of the conical tank used 
for this project. In this process inflow is the manipulated variable and the level of the tank will be

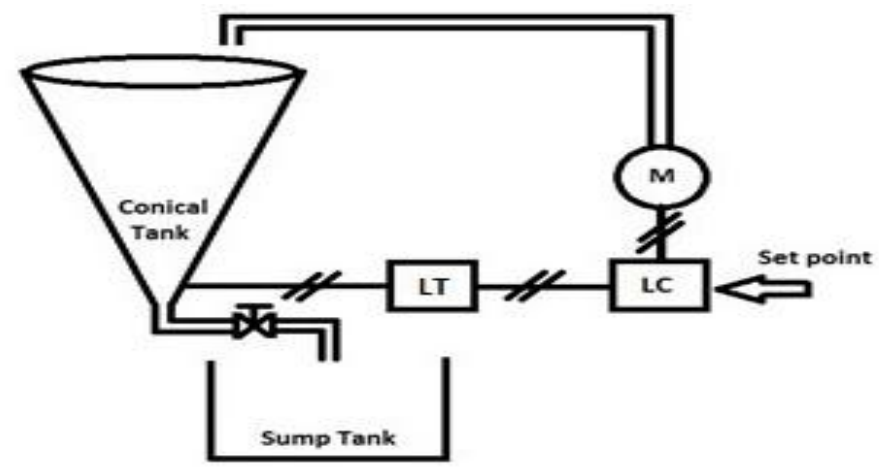

the controlled variable.

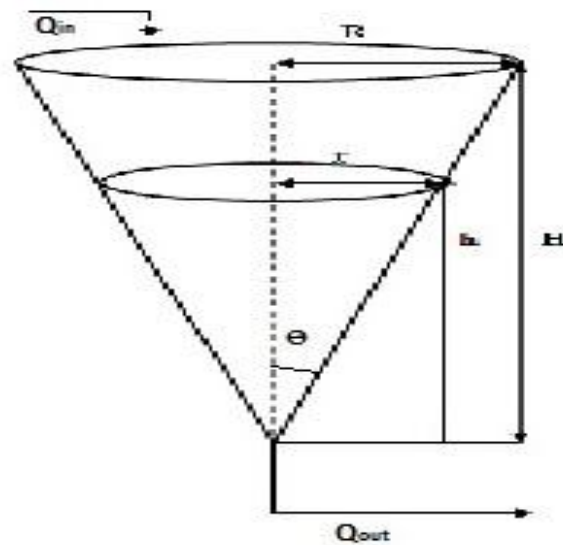

Figure 1 Functional diagram

Here,

Qin $=$ Rate of inflow into the tank

Qout = Rate of outflow from the tank

$\mathrm{H}=$ Total height of the tank

$\mathrm{R}=$ Top radius of the tank

$\mathrm{h}=$ Height of the liquid in the conical tank

$r=$ Radius of the liquid in the conical tank

$\mathrm{K}=$ Valves coefficient

Volume of cone $=\frac{1}{3} \pi r^{2} \cdot \mathrm{h}$

Area of cone ' $\mathrm{A}$ ' $=\pi r^{2}$

$\tan \theta=\frac{r}{h}=\frac{R}{H}$

$$
r=R \cdot \frac{h}{H}
$$

According to the law of conservation of mass,

Accumulation $=$ Inflow rate - Outflow rate

Qin - Qout $=\mathrm{A} \frac{d h}{d t}$

From equation 1 and 2 ,

Area, $\mathrm{A}=\frac{\pi \cdot R^{2} \cdot \mathrm{h}^{2}}{H^{2}}$

So,

Qin - Qout $=\frac{1}{3} \cdot\left(A \frac{d h}{d t}+\frac{h \cdot\left(2 \pi \cdot R^{2} \cdot h \cdot \frac{1}{H^{2}}\right) d h}{d t}\right)$

Now as the outflow Qout is a function of height of the liquid and valve coefficient $\mathrm{K}$.

So,

Qout $(\mathrm{s})=\frac{1}{K s} \cdot h(s)$

Putting the value of Qout in equation 7,

$$
\begin{aligned}
& \frac{Q_{i n}(s)}{s}-\frac{1}{K s} \cdot h(s)=\frac{1}{3} \cdot\left(A \cdot h(s)+h \cdot\left(\frac{2 \pi \cdot R^{2} \cdot h}{H^{2}}\right) \cdot h(s)\right) \\
& \frac{Q_{\text {in }}(s)}{s}-\frac{1}{K s} \cdot h(s)=\frac{1}{3} \cdot h(s) \cdot\left(A+h \cdot\left(\frac{2 \pi \cdot R^{2} \cdot h}{H^{2}}\right)\right. \\
& \frac{Q_{\text {in }}(s)}{s}=\frac{1}{3} \cdot h(s) \cdot\left(A+h \cdot\left(\frac{2 \pi \cdot R^{2} \cdot h}{H^{2}}\right)+\frac{1}{K s} \cdot h(s)\right) \\
& \frac{Q_{\text {in }}(s)}{s}=h(s) \cdot \frac{1}{3} \cdot\left(A+h \cdot\left(\frac{2 \pi \cdot R^{2} \cdot h}{H^{2}}\right)+\frac{1}{K s}\right) \\
& \frac{Q_{i n}(s)}{s}=\frac{h(s) \cdot\left(\frac{1}{3} \cdot A+\frac{2 \pi \cdot R^{2} \cdot h^{2}}{3 H^{2}}+\frac{1}{K s}\right)}{\frac{Q_{i n}(s)}{s}}=h(s) \frac{\left(A \cdot H^{2} \cdot K s+2 \cdot \pi \cdot R^{2} \cdot h^{2} \cdot K s+3 \cdot H^{2}\right)}{3 \cdot H^{2} \cdot K s} \\
& \frac{h(s)}{Q_{i n}(s)}=\frac{1}{s} \cdot \frac{3 \cdot H^{2} \cdot K s}{A \cdot H^{2} \cdot K s+2 \cdot \pi \cdot R^{2} \cdot h^{2} \cdot K s+3 \cdot H^{2}} \\
& \frac{h(s)}{Q_{i n}(s)}=\frac{3 \cdot H^{2} \cdot K}{\left(A \cdot H^{2}+2 \cdot \pi \cdot R^{2} \cdot h^{2}\right) K s+3 \cdot H^{2}} \\
& \frac{h(s)}{Q_{i n}(s)}=\frac{K}{\left(\frac{A \cdot H^{2}+2 \cdot \pi \cdot R^{2} \cdot h^{2}}{3 \cdot H^{2}}\right) K s+1}
\end{aligned}
$$

So from the above transfer function, it can be said that as the height of the water inside the conical tank will change, the transfer function of the process will also change [4].

By changing ' $h$ ' i.e. the height of the water level inside the tank, different transfer function that are found are as shown: 
At water level of $10 \mathrm{~cm}$ :

Area of the tank, A:

$1130.4 \mathrm{~cm}$

Total height of the tank, $\mathrm{H}$ :

Height of the water level, h:

Top radius of the tank, $\mathrm{R}$ :

Valve coefficient, $\mathrm{K}$ :

$4 \mathrm{~cm}$

$10 \mathrm{~cm}$

$10 \mathrm{~cm}$

75.709

$\frac{h(s)}{Q_{\text {in }}(s)}=\frac{K}{\left(\frac{A \cdot H^{2}+2 \cdot \pi \cdot R^{2} \cdot h^{2}}{3 \cdot H^{2}}\right) K s+1}$

$=\frac{75.709}{31278.6126 s+1}$

At water level of $15 \mathrm{~cm}$ :

Area of the tank, A:

Total height of the tank, $\mathrm{H}$ :

Height of the water level, h:

Top radius of the tank, $\mathrm{R}$ :

Valve coefficient, $\mathrm{K}$ :

$1130.4 \mathrm{~cm}$

$24 \mathrm{~cm}$

$15 \mathrm{~cm}$

$10 \mathrm{~cm}$

75.709

$$
\frac{h(s)}{Q_{\text {in }}(s)}=\frac{K}{\left(\frac{A \cdot H^{2}+2 . \pi \cdot R^{2} \cdot h^{2}}{3 \cdot H^{2}}\right) K s+1}=\frac{75.709}{34717.9392 s+1}
$$

At water level of $20 \mathrm{~cm}$ :

Area of the tank, A:

$1130.4 \mathrm{~cm}$

Total height of the tank, $\mathrm{H}$ :

Height of the water level, h:

Top radius of the tank, $\mathrm{R}$ :

Valve coefficient, K:

$24 \mathrm{~cm}$

$15 \mathrm{~cm}$

$10 \mathrm{~cm}$

75.709

$\frac{h(s)}{Q_{i n}(s)}=\frac{K}{\left(\frac{A \cdot H^{2}+2 \cdot \pi \cdot R^{2} \cdot h^{2}}{3 \cdot H^{2}}\right) K s+1}$

$=\frac{75.709}{39532.9966 s+1}$

\section{System integration and hardware development}

In order to develop a test bench for a non-linear process a conical tank control system is developed. To measure the level of the water inside the tank an integrated pressure sensor MPXV5004G is used. The hydrostatic pressure generated by the volume of the water inside the conical tank is converted into the voltage. It gives output in the range of $0-5$ volts. The output of the pressure sensor is calibrated in terms of height of water inside the tank. The level of water is controlled by manipulating the speed of the diaphragm pump to control the rate of inflow. L293D motor driver IC is used to control the speed of the 24v DC pump through the control signals received from the Arduino Uno R3 board.

So as the integrated pressure sensor senses the height of water level inside the conical tank it gives its values to the Arduino board which is connected to the LabVIEW program. Based on the error generated between the set point and the height of the water level sensed by the integrated pressure sensor PID controller takes action and accordingly generates PWM signals. These PWM signals are fed to the
Arduino board. Based on the PWM signals, Arduino Uno then generates electrical signals to control the diaphragm pump which controls the water inlet inside the tank. In this manner the water level inside the conical tank is controlled.

Figure 2 shows the hardware setup used as the test bench. The test bench includes a conical tank along with the diaphragm pump and a controller box. A manual valve is also placed between the sump tank and the conical tank in order to introduce disturbance when needed. Table 1 shows the specifications of the conical tank being used in the test bench. Figure 3 shows the inside of the controller box consisting of an Arduino board, an SMPS, a motor driver IC and the pressure sensor.

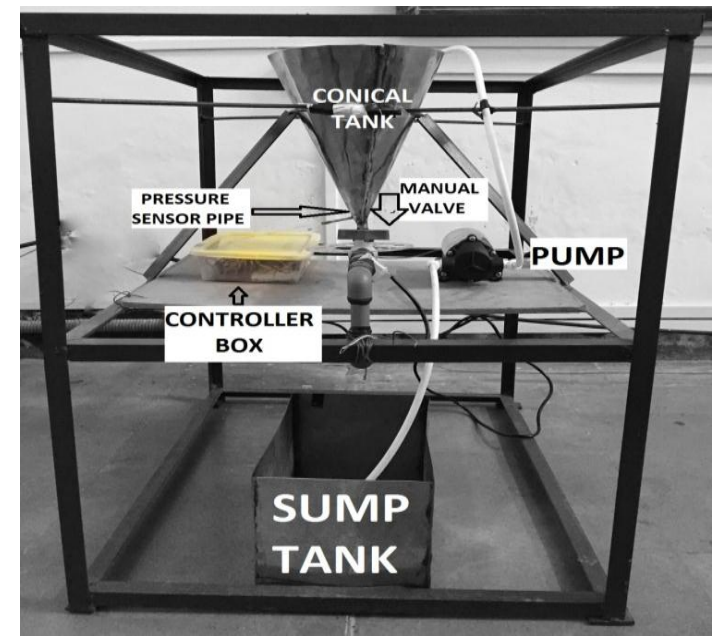

Figure 2 Conical tank system

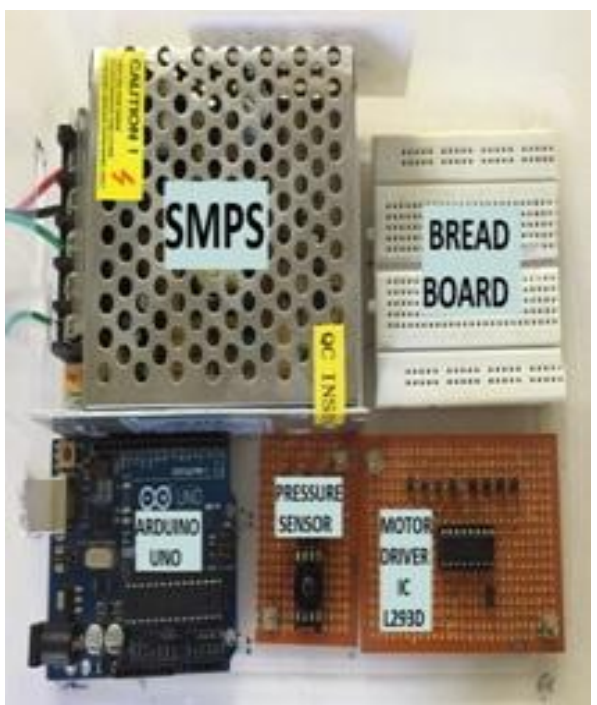

Figure 3 Controller box 
Table 1 Specification of conical tank

\begin{tabular}{ll}
\hline Height & 12 Inches \\
\hline Upper radius & 4.25 inches \\
Lower radius & 0.25 inches \\
Volume & 226.98 cubic inches $=3.72$ litres \\
\hline
\end{tabular}

Here in Figure 4 a graph is plotted of volume inside the conical tank versus the sensor output which is indicating the height of the tank. So as the volume of the liquid increases inside the tank, the output of the pressure sensor depicts the non-linearity in its behaviour. Therefore this chart shows that the output of the conical tank is non-linear in nature.

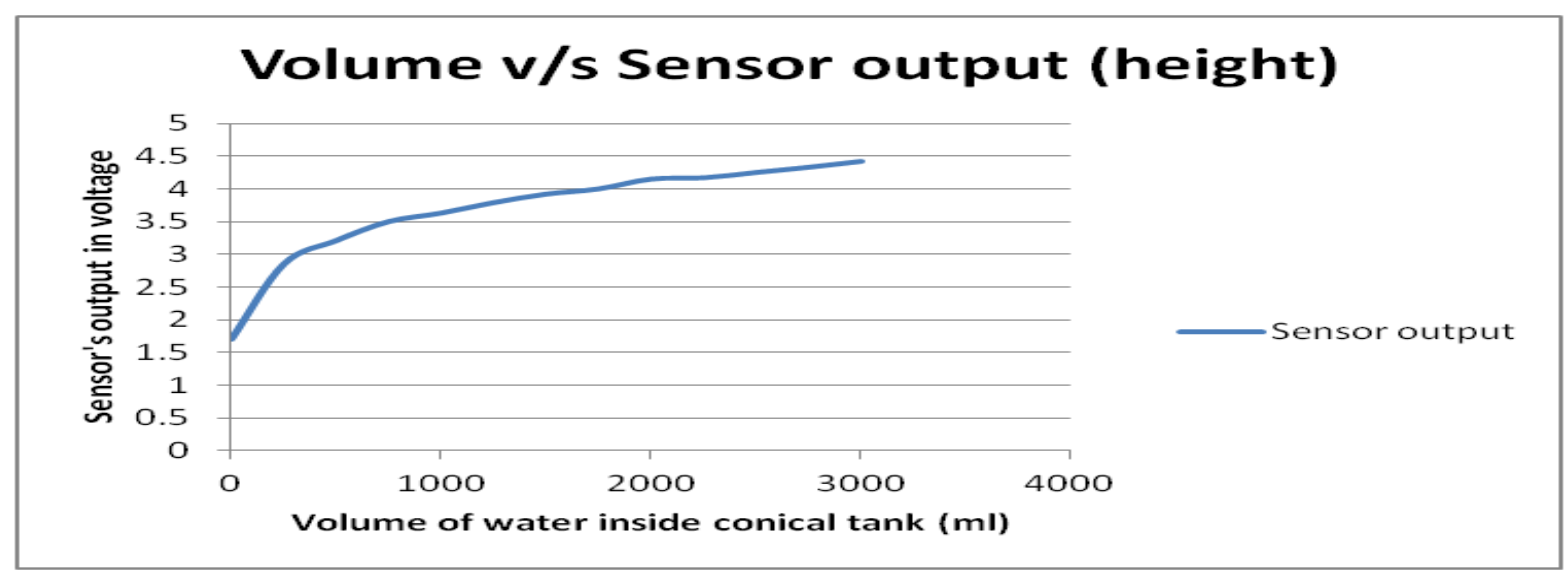

Figure 4 Non-linear output of conical tank

\section{Results}

As the non-linearity of the conical system is proved, now the effect of controller at different operating points is studied and following results were found that are shown in Figure 5. Here the controller's settings that are being used are kept $\mathrm{Kp}=12, \mathrm{Ti}=0$, $\mathrm{Td}=0$ first. Simulation results obtained from the MATLAB for the transfer function that are presented above showed that these PID settings are working fine with different water levels. By keeping the same controller settings, different step changes were applied to the system to check the difference in its behaviour at all these step changes. The graph below shows the normalized step change versus the performance of the controller with different step changes. Two different PID settings i.e $\mathrm{Kp}=5$, $\mathrm{Ti}=0$, $\mathrm{Td}=0$ and $\mathrm{Kp}=20, \mathrm{Ti}=0, \mathrm{Td}=0$ are also used in order to study their response upon applying different step changes by keeping same PID settings. Result of these other two graphs confirms that the response of conical tank system changes with different step changes even at different PID settings. So it can be affirmatively said that the conical tank system depicts non-linearity with every PID settings.

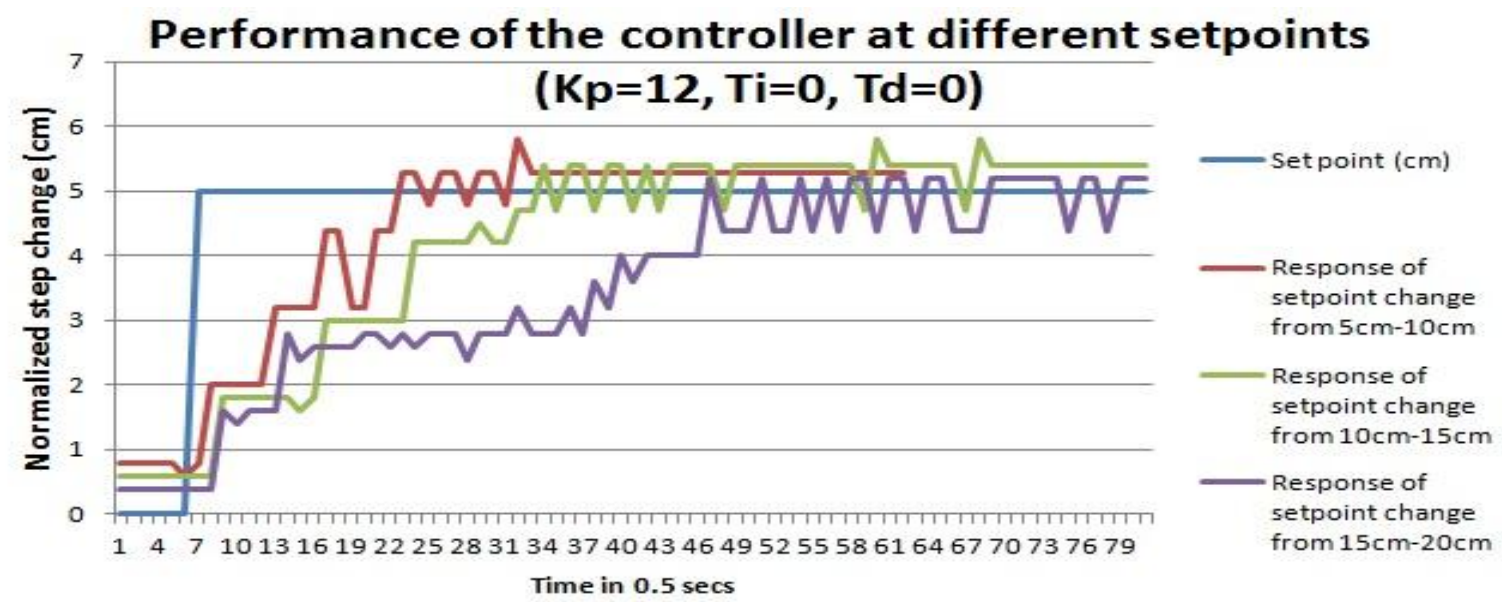



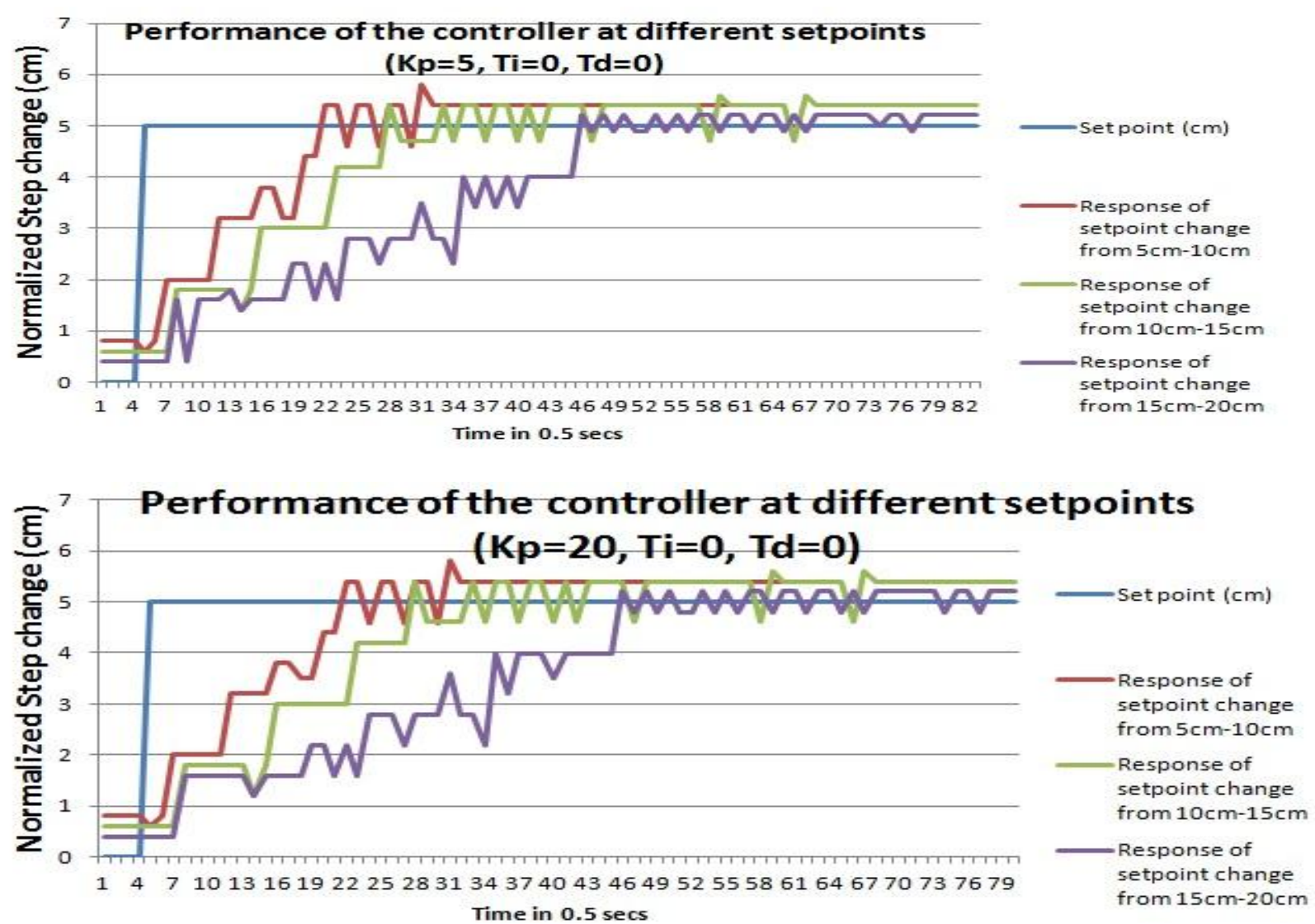

Figure 5 Performance of the controller with different step changes and with different PID settings

\section{Analysis}

As the transfer functions for different water levels are derived, it is seen that the time constant of the process keeps changing as the water level changes. These results are shown in Table 2. This in here proves the non-linearity of the process and it also signifies that the behavior of the process is in such a fashion that as the water level increases the process is taking more and more time to settle.

Table 2 Values of time constant at different water levels

\begin{tabular}{ll}
\hline Water level $(\mathbf{C m})$ & Time constant $($ Sec) \\
\hline 10 & 31278.6126 \\
15 & 34717.9392 \\
20 & 39532.9966 \\
\hline
\end{tabular}

Now when the empirical results were taken from the test bench by keeping different set points, similar results were depicted as shown by the theoretical study. It can be easily seen from Figure 5 that the response of set point change from $5 \mathrm{~cm}$ to $10 \mathrm{~cm}$ is taking lesser time to achieve the desired set point while the time taken to achieve same step change keeps on increasing as the water level is increased. Table 3 shows increasing settling time with the increase in set points. This proves the analysis that was first inferred from the theoretical analysis.

Therefore from the above table it can be said that the same PID settings cannot work in similar fashion for all the given set points. This also proves that PID controller that is very successful in controlling any linear process is not very efficient for the control of a non-linear process [5].

Table 3 Empirical results at different step changes

\begin{tabular}{|c|c|c|c|c|c|c|}
\hline \multicolumn{3}{|c|}{$\begin{array}{l}\text { Controllers' } \\
\text { settings }\end{array}$} & \multirow[t]{2}{*}{$\begin{array}{l}\text { Step } \\
\text { change }\end{array}$} & \multirow[t]{2}{*}{$\begin{array}{l}\text { Settling } \\
\text { time }\end{array}$} & \multirow[t]{2}{*}{$\begin{array}{l}\text { Rise } \\
\text { time }\end{array}$} & \multirow{2}{*}{$\begin{array}{l}\text { Over- } \\
\text { shoot } \\
\%\end{array}$} \\
\hline Kc & $\mathbf{T i}$ & Td & & & & \\
\hline 12 & 0 & 0 & $\begin{array}{l}10 \mathrm{~cm}- \\
15 \mathrm{~cm} \\
(5 \mathrm{~cm})\end{array}$ & $8 \mathrm{sec}$ & $6 \mathrm{sec}$ & 5.96 \\
\hline 12 & 0 & 0 & $\begin{array}{l}15 \mathrm{~cm}- \\
20 \mathrm{~cm} \\
(5 \mathrm{~cm})\end{array}$ & $13.5 \mathrm{sec}$ & $\begin{array}{l}12 \\
\sec \end{array}$ & 7.97 \\
\hline 12 & 0 & 0 & $\begin{array}{l}15 \mathrm{~cm}- \\
20 \mathrm{~cm} \\
(5 \mathrm{~cm})\end{array}$ & $20 \mathrm{sec}$ & $\begin{array}{l}18.5 \\
\text { sec }\end{array}$ & 3.92 \\
\hline
\end{tabular}




\section{Conclusion}

From the result and analysis of this paper it can be concluded that a conical tank is a good example of a non-linear system. It is also found through the empirical results on the test bench that to control a non-linear system a single PID setting cannot work with same efficiency for all the given set points. Application of gain scheduling, MPC [6], adaptive PID or other advanced control strategy [7] becomes a necessity in order to control the non-linear system satisfactorily. In future, gain scheduling with a proper truth table with different control settings for different set points will be applied on to the non-linear test bench through an Arduino board in order to build a low cost embedded system to control a non-linear system.

\section{Acknowledgment}

None.

\section{Conflicts of interest}

The authors have no conflicts of interest to declare.

\section{References}

[1] Anand S, Aswin V, Kumar SR. Simple tuned adaptive PI controller for conical tank process. In international conference on recent advancements in electrical, electronics and control engineering 2011 (pp. 263-7). IEEE.

[2] Gireesh N, Sreenivasulu G. Comparison of PI controller performances for a conical tank process using different tuning methods. In international conference on advances in electrical engineering 2014 (pp. 1-4). IEEE.

[3] Blum W, Ferri RB. Mathematical modelling: can it be taught and learnt? Journal of Mathematical Modelling and application. 2009; 1(1):45-58.

[4] Pushpaveni T, Srinivasulu Raju S, Archana N, Chandana M. Modeling and Controlling of Conical tank system using adaptive controllers and performance comparison with conventional PID. International Journal of Scientific \& Engineering Research. 2013; 4(5):629-35.

[5] Janarthanan S, Thirukkuralkani KN, Vijayachitra S. Performance analysis of non-integer order PID controller for liquid level control of conical tank system. In international conference on information communication and embedded systems 2014 (pp. 1-5). IEEE.

[6] Warier SR, Venkatesh S. Design of controllers based on mpc for a conical tank system. In international conference on advances in engineering, science and management 2012. IEEE.
[7] Nithya S, Gour AS, Radhakrishnan TK, Balasubramanian $\mathrm{T}$, Anantharaman $\mathrm{N}$. Intelligent controller implementation in real time for a nonlinear process. In IEEE international symposium on industrial electronics 2008 (pp. 2508-13). IEEE.

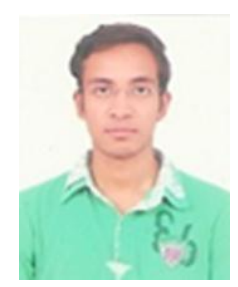

Harshit Bhadauriya completed B.Tech in Electronics and Instrumentation Engineering from Northern India Engineering College, Lucknow in 2013 and now he is an M.Tech final year student in Instrumentation and control branch at Institute of technology, Nirma University, Ahmedabad. He recived 'Best paper award' for this paper at National conference on process automation and control organized by MNIT, Jaipur.

Email:14micc12@nirmauni.ac.in

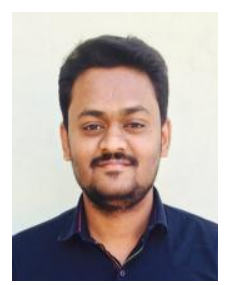

Harsh Kapadia holds M.Tech in Instrumentation \& Control Engineering from Dharmsinh Desai University, Nadiad. He is currently working as Assistant Professor in Instrumentation and Conrol Engineering, Institute of Technology, Nirma University. His research focuses on Sensors and signal conditioning, Image processing, Machine Vision, Embedded system, Embeded vision, Vision based control.

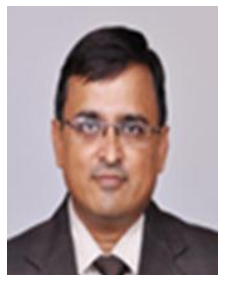

Prof. Jignesh Patel has 20 years of teaching experience. He is conferred with Institue Silver Medal (Year 2002) at Indian Institute of Technlogy, Kharagpur for his outstanding performance and Rank \#1 in Post Graduate Programme. Prof. Patel has published more than 20 papers in National/International Conferences and Journals. At present he looks after the activities of Centre for continuing Education, Nirma University, He is head of CCE.

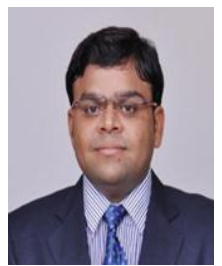

Alpesh Patel has Master degree in Instrumentation and Control (Applied Instrumentation) from LD college of Engineering, Gujarat Technological University with Gold medal. Prof. Alpesh Patel has published more than 06 papers in National/International Conferences and Journals. His research interests in Process Modelling and Advanced process control. He has very good command onProgrammable Logic Controller, SCADA, Process Control and Industrial Automation. 